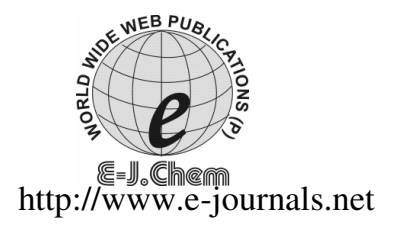

ISSN: 0973-4945; CODEN ECJHAO

E-Journal of Chemistry

2010, 7(1), 21-24

\title{
A Computational Approach towards the Development of Newer Anticancer Agents
}

\author{
JAVED I. SHEIKH*, H. D. JUNEJA and V. N. INGLE \\ Organic Chemistry Research Laboratory, \\ Department of Chemistry, RTM Nagpur University, Nagpur-440 033, India. \\ javedchemie@gmail.com
}

Received 10 January 2009; Accepted 5 March 2009

\begin{abstract}
In silico molecular docking analyses of the novel 1-(2', 4'dihydroxy-5'-chlorophenyl)-3-aryl-propane-1,3-diones were performed in the active sites of enzyme cytochrome P450 reductase to obtain new anticancer agents computationally. 1-(2', 4'-dihydroxy-5'-chlorophenyl)-3-(4"-methoxyphenyl)-propane-1, 3-dione (3f) was found to have maximum affinity for the active sites of enzyme.
\end{abstract}

Keywords: Dibenzoylmethane, Cytochrome P450 reductase, In silico docking analysis.

\section{Introduction}

Drug development requires detailed information about the biological activity of the pharmacological compounds against selected targets. The application of computational methods to study the formation of intermolecular complexes has been the subject of intensive research during the last decade. It is widely accepted that drug activity is obtained through the molecular binding of one molecule (the ligand) to the pocket of another, usually larger, molecule (the receptor), which is commonly a protein ${ }^{1-10}$.

Dibenzoylmethane (DBM) 1, a $\beta$-diketone structural analogue of curcumine, has received attention in recent years because of its potent anticarcinogenic activity against 7, 12-dimethylbenz[a]anthracene (DMBA) induced mammary tumorigenesis tested in several animal models ${ }^{11,12}$.

DMBA, an effective carcinogenic initiator, is metabolically activated by cytochrome P450 oxidase to electrophilic diol-epoxide intermediate, which subsequently interact with DNA to form DMBA-DNA adducts ${ }^{13-18}$. However the $\beta$-diketone functionality in DBM is reduced through the action of liver microsomes, in which cytochrome reductase is thought to be responsible for the reduction. The isolated reductive metabolites of DBM would imply the potential role of DBM as an inhibitor of cytochrome $\mathrm{P} 450$ reducatse that is required for the function of cytochrome P450 oxidase to metabolize DMBA, resulting in the inhibitory effect on DMBA-induced mouse mammary tumorigenesis ${ }^{19}$. 
<smiles>O=C(CC(=O)c1ccccc1)c1ccccc1</smiles><smiles>O=C(CC(=O)c1ccccc1)c1ccccc1</smiles>

\section{.Scheme 1.}

The said inhibitory effect of DBM on cytochrome P450 reductase provides the root for molecular docking experiments to dock the newly synthesized 1-(2', 4'-dihydroxy-5'chlorophenyl)-3-aryl-propane-1, 3-diones (3a-h) ${ }^{20}$ in the active sites of cytochrome P450 reductase and to study the binding affinity. The compound $\mathbf{3 a - h}$ was derived from the modification of the initial lead compound DBM (1). Structure 2 shows sites of modification (Scheme 1).

\section{Experimental}

The newly synthesized 1-(2', 4'-diydroxy-5'-chlorophenyl)-3-aryl-propane-1, 3-diones (3a-h) endowed with cytochrome $\mathrm{P} 450$ reductase inhibition, each compound was energy minimized using the Universal force-field v.1.2 and the docking calculations were performed using Argus Lab v 4.0 into the 3D model of the catalytic site of cytochrome P450 reductase enzyme. It should be mentioned that the Lamarckian genetic algorithm (LGA) implemented in Argust Lab has been successfully employed to dock inhibitors into the catalytic site of the cytochrome P450 reductase and to well correlate the obtained binding free energies with inhibitory activities of compounds. Briefly, we carried out comparative docking experiments of synthesized new compound 3a-h with known selective inhibitors of cytochrome P450 reductase such as dibenzoylmethane. The obtained results were evaluated in terms of binding energy and docking poses into the catalytic site of cytochrome P450 reductase. Figure 1 show docking pose of the 3f. List of 1-(2', 4'-diydroxy-5'-chlorophenyl)-3-aryl-propane-1, 3-diones 3a-h endowed into the catalytic site of cytochrome $\mathrm{P} 450$ reductase are:<smiles>O=C(CC(=O)c1cc(Cl)c(O)cc1O)c1ccc(P)cc1</smiles>
$\mathrm{R}=$ 3a. $\mathrm{H}$
3e. 3-Methoxy
3b. 2-Chloro
3f. 4-Methoxy
3c. 3-Chloro
3g. 3-Methyl
3d. 4-Chloro
3h. 4-Methyl
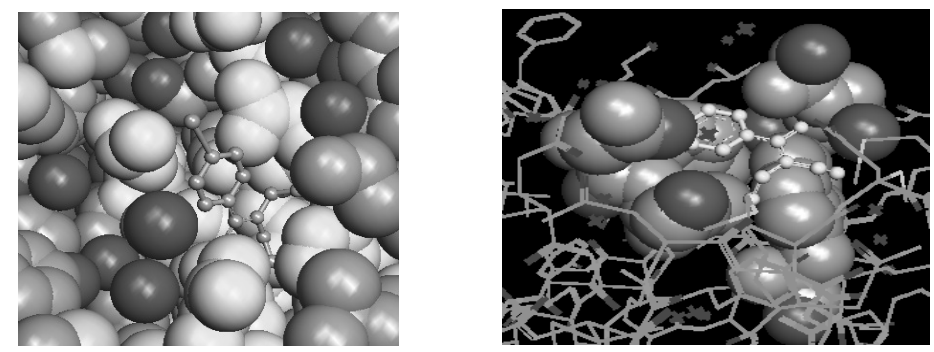

Figure 1. 1-(2', 4'-Diydroxy-5'-chlorophenyl)-3-(4"-methoxyphenyl)-propane-1,3-dione (3f) in the active site of cytochrome P450 reductase using Argus \& Genetic algorithms having binding free energies -8.68 and $-9.24 \mathrm{kcal} / \mathrm{mole}$ respectively. 


\section{Results and Discussion}

The results obtained are given in Table 1. The low binding free energies for the inhibitors means, the high binding affinity, more readily will the inhibitor binds with enzyme in its binding pocket to block its function. The binding free energy for the lead compound dibenzoylmethane is -7.69 and $-8.02 \mathrm{kcal} / \mathrm{mole}$ using Argus and Genetic algorithms respectively as shown in Table 1 . However the binding free energies calculated using Argus and Genetic algorithms for some of the 3a-h viz., 3a, 3c, 3d and $\mathbf{3 f}$ are -7.64, -8.34; -8.02, $7.32 ;-9.34,-8.92$ and $-9.87,-8.43$ respectively, are even lower than the binding free energy of lead compound dibenzoylmethane (1). Thus by employing computational drug designing a new lead compound (3f) were obtained having the lowest binding free energy (i.e. -9.87 and $-8.43 \mathrm{kcal} / \mathrm{mole}$ respectively using Argus and Genetic algorithms) among the other (3a-h).

Table 1. Docking analysis of 1-(2', 4'-diydroxy-5'-chlorophenyl)-3-aryl-propane-1, 3-diones $(\mathbf{3 a}-\mathbf{h})$ with cytochrome $\mathrm{P} 450$ reductase showing binding free energies<smiles>[R]c1ccc(C(=O)CC(=O)c2cc(Cl)c(O)cc2O)cc1</smiles>

\begin{tabular}{ccc}
\hline \multirow{2}{*}{ Ligand } & \multicolumn{2}{c}{ Binding Energies, kcal/mole } \\
\cline { 2 - 3 } & Argust algorithm & Genetic algorithm \\
\hline 3a & -7.64 & -8.38 \\
3b & -6.47 & -6.90 \\
3c & -8.02 & -7.32 \\
3d & -9.34 & -8.92 \\
3e & -7.93 & -6.57 \\
3f & -9.87 & -8.43 \\
3g & -6.94 & -6.81 \\
3h & -7.43 & -8.01 \\
DBM & -7.69 & -8.02 \\
\hline
\end{tabular}

\section{Conclusion}

Herein, we report computational development of a new series of compounds (3a-h) by modifying the lead compound DBM to inhibit cytochrome P450 reductase and compound $\mathbf{3 f}$ found to have maximum binding affinity towards the enzyme.<smiles>COc1ccc(C(=O)CC(=O)c2cc(Cl)c(O)cc2O)cc1</smiles>

\section{Acknowledgement}

We expressed our sincere thanks to the Head, Department of Chemistry, RMT Nagpur University, Nagpur for providing necessary facilities required to shape out the work.

\section{References}

1 Vieth M, Hirst J D, Kolinski A and Brooks C L I, J Comput Chem., 1998, 19, 1612. 
2 MacKerell A D, Bashford D, Bellot M, Karplus M and et al., J Phys Chem B., 1998, $\mathbf{1 0 2}, 3586$.

3. Cornell W D, J Am Chem Soc., 1995, 117, 5179.

4. Morris G M, J Comput Chem., 1998, 19, 1639.

5. $\quad$ Ewing T J A and Kuntz I D, J Comput Chem., 1997, 18, 1175.

6. Kramer B, Metz G, Rarey M and Lengauer T, Med Chem Res., 1999, 9, 463.

7. Solis F J and Wets R J B, Math Oper Res., 1981, 6, 19.

8. $\quad$ Makino S, Ewing T J and Kuntz I D, J Comput Aided Mol Des., 1999, 13, 513.

9. Goldman B B and Wipke W T, Proteins, 2000, 38, 79.

10. Taylor J S and Burnett R M, Proteins, 2000, 41, 173.

11. Huang M T, Lou Y R, Xie J G, Ma W, Lu Y P, Yen P and Zhu B T, Carcinogenesis, 1998, 19, 1697.

12. Singletary K, MacDonald C, Iovinelli M, Fisher C and Walling M, Carcinogenesis, 1998, 19, 1039.

13. Wood A W, Levin W, Chang R L, Yagi H, Thaker D R, Lehr R E, Jerina D M and Conney A H, Polynuclear aromatic hydrocarbons; Jones P W \& Leber P Eds. Ann Arbor Science Publishers. Michigan, U S A, 1979, 531.

14. Lu AY H, Junk K W and Coon M J, J Biol Chem., 1969, 244, 3714.

15. Ravindranath V and Chandrasekhara N, Toxicolgy, 1981, 20, 251.

16. Kitamura S and Tatsumi K, Arch Biochem Biophys., 1990, 282, 183.

17. Pan M H, Huang T M and Lin J K, Drug Metab Dispos., 1999, 27, 486.

18. Hall M and Grover P L, Handbook of Experimental Pharmacology; Cooper C S \& Grover P L Eds. Springer-Verlag, New York, U S A, 1990, 327.

19. Lin C-C, Wei G J, Huang M T and Ho C T, J Food and Drug Analysis, 2005, 13(3), 284.

20. Sheikh J I, Ingle V N and Juneja H D, E Journal of Chemistry, 2009, 6, 705 


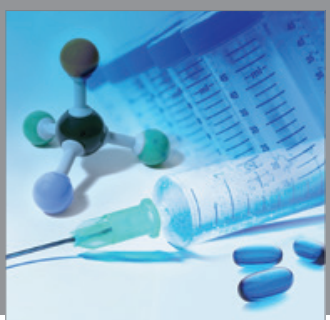

International Journal of

Medicinal Chemistry

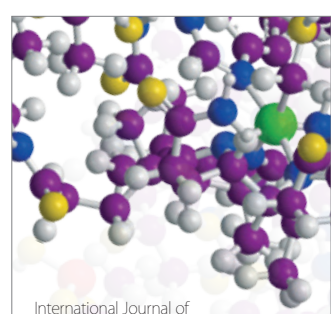

Carbohydrate Chemistry

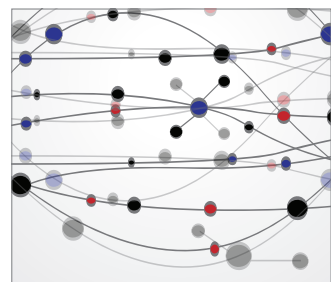

The Scientific World Journal
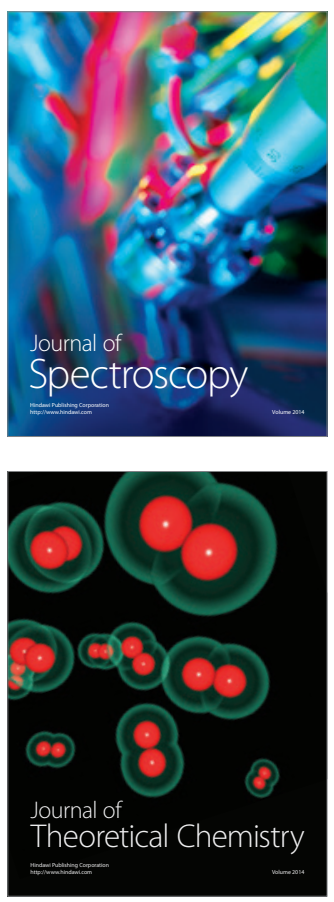
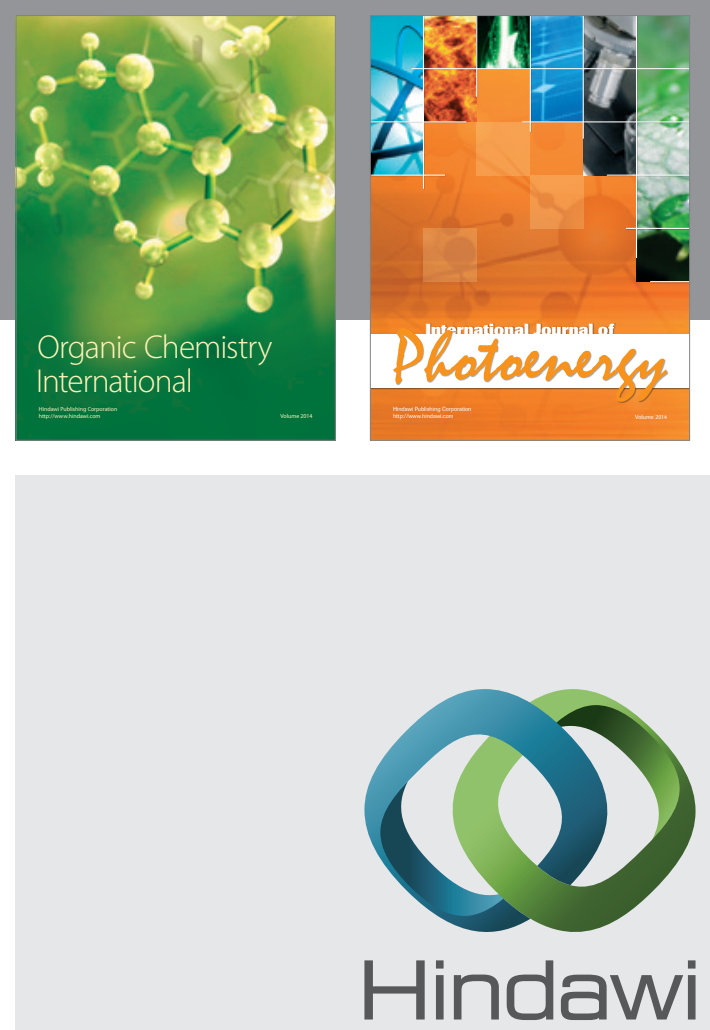

Submit your manuscripts at

http://www.hindawi.com
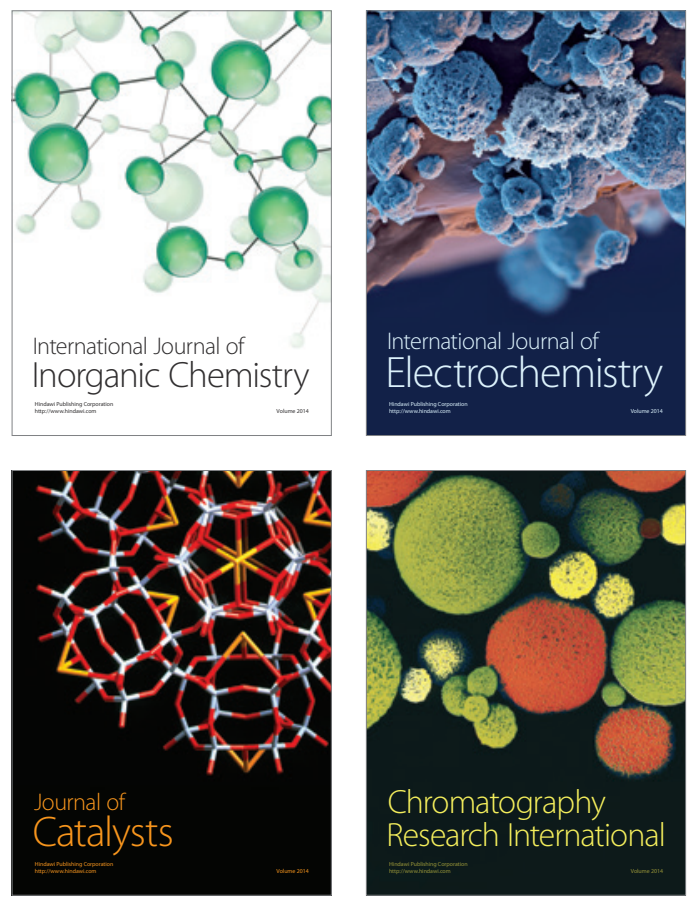
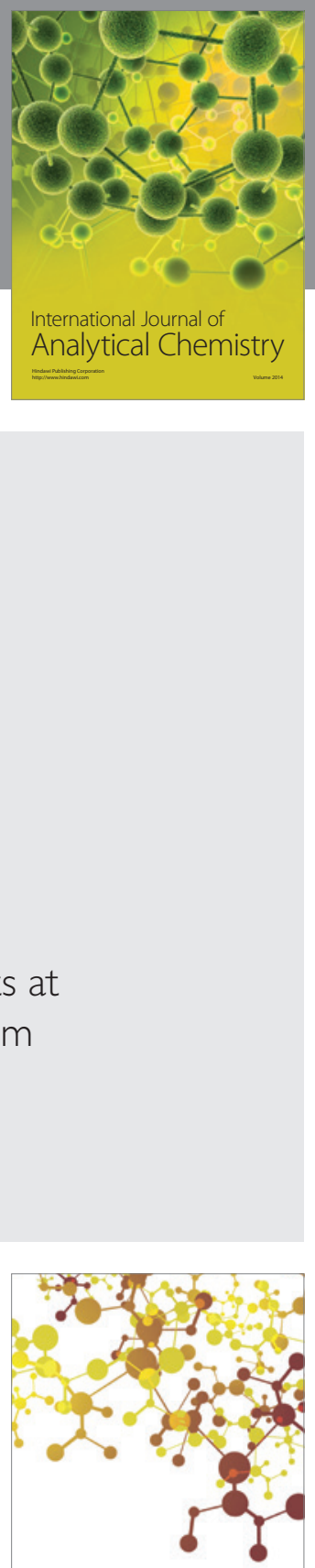

Journal of

Applied Chemistry
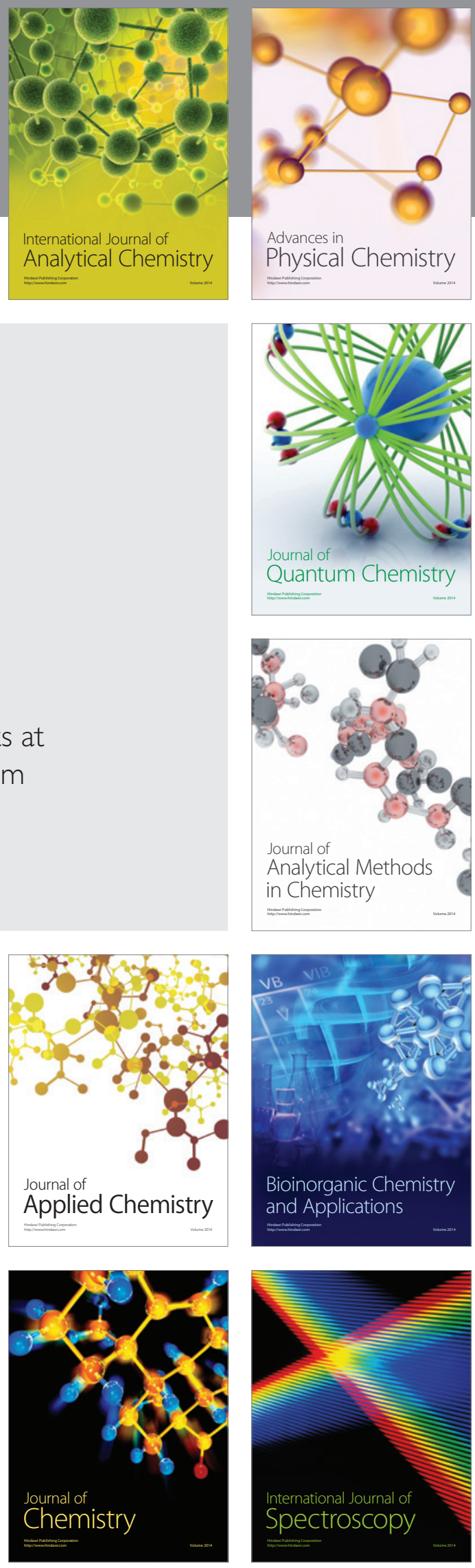